UNIWERSYTET JAGIELLOŃSKI

\title{
KARMELITAŃSKI INWENTARZ MUZYCZNY Z I739 ROKU
}

onad czterdzieści lat temu, w I977 r., na łamach Muzyki Tadeusz Maciejewski
napisał, że „archiwa, biblioteki klasztorne i kościelne, zbiory państwowe kryją jeszcze sporo tajemnic. Mimo zaawansowanych prac poszukiwawczych zawsze można liczyć na odkrycie nieznanych dokumentów, co w pewnym stopniu usprawiedliwia wędrówki szlakami kiedyś już przetartymi”' . Postulat ten jest nadal aktualny. Okazuje się, że warto przyjrzeć się ponownie także zbiorom zgromadzonym w Archiwum Karmelitów w Krakowie na Piasku, bo chociaż posłużyły one Tadeuszowi Maciejewskiemu do napisania kilku pionierskich i bardzo wartościowych prac poświęconych kulturze muzycznej ośrodków karmelitańskich, muzykolog nie wyzyskał wszystkich informacji w nich zawartych².

W zbiorach klasztornych odnajdywane są również kolejne nieznane źródła do historii muzyki. Nieznany był dotąd karmelitański inwentarz muzyczny z I739 r.,

I Tadeusz Maciejewski, „O Eliaszu Karmelicie, Wawrzyńcu Zadorskim - warszawskim organmistrzu i Gabrielu Seneńskim - trębaczu”, Muzyka 22 (I977) nr 3, s. III.

2 Pierwsze wzmianki na temat kultury muzycznej karmelitów na Piasku można odnaleźć w artykule Jerzego Gołosa, „Muzykalia biblioteki klasztoru Na Piasku w Krakowie”, Muzyka II (I966) nr 3/4, s. 86-97. Systematyczne badania nad kulturą muzyczną karmelitów dawnej obserwy zainicjował Tadeusz Maciejewski w 1975 r., publikując artykuł o charakterze przyczynkowym, zob.: Tadeusz Maciejewski, „Przyczynek do biografii Andrzeja Wołoszki (ca I700-I757) i do historii kapel karmelickich”, Muzyka 20 (1975) nr 2, s. 73-8I. Przeprowadzona przez badacza kwerenda w archiwum prowincjalnym karmelitów w Krakowie zaowocowała kolejnymi publikacjami: Tadeusz Chrzanowski, Tadeusz Maciejewski, Graduat karmelitański z I644 r. o. Stanistawa ze Stolca, Warszawa 1976; Tadeusz Maciejewski, „Inwentarz muzykaliów kapeli karmelickiej w Krakowie na Piasku z lat I665-I684”, Muzyka 2I (I976) nr 2, s. 77-99; T. Maciejewski, „O Eliaszu Karmelicie”, s. III-II5; Tadeusz Maciejewski, „Działalność muzyczna Bractwa Szkaplerznego w kościele oo. Karmelitów Trzewiczkowych w Krakowie na Piasku”, Muzyka 23 (1978) nr 2, s. 59-7I; Tadeusz Maciejewski, „Kilka uwag o muzyce i muzykach z klasztoru oo. Karmelitów Trzewiczkowych w Trembowli”, w: Musica Galiciana. Kultura muzyczna Galicji w kontekście stosunków polsko-ukraińskich (od doby piastowsko-książęcej do roku I945), red. Leszek Mazepa, t. 3, Rzeszów 1999, s. I27-I37; Tadeusz Maciejewski, „Muzycy karmeliccy z lwowskiego Conventus Major”, w: Musica Galiciana. Kultura muzyczna Galicji w kontekście stosunków polsko-ukrainskich (od doby piastowsko-książęcej do roku 1945), red. Leszek Mazepa, t. 5, Rzeszów 2000, s. 23-44. 
który - nieodnotowany w drukowanym katalogu zbiorów archiwalnych - nie stał się przedmiotem zainteresowania muzykologów3 . Na ten cenny zabytek zwrócił moją uwagę dr Szymon Sułecki - kierownik Archiwum Karmelitów w Krakowie na Piasku, za co w tym miejscu składam mu serdeczne podziękowanie.

Inwentarz, o którym mowa, został włączony do zbiorów bibliotecznych oo. Karmelitów na Piasku, a nie do archiwum karmelitańskiego, prawdopodobnie jeszcze w XIX w. i z tego powodu umknął uwadze badaczy. W katalogu zbiorów bibliotecznych ukończonym w 1957 r., spisanym z autopsji, opisane zostały kolejne książki umieszczone w szafach bibliotecznych. W szafie XIV pod numerem 193 znajdowała się pozycja pt. Litaniae Lauretanae (rękopis) - pótka 6 od góry, która okazała się cennym rękopiśmiennym inwentarzem muzykaliów z XVIII wieku. W katalogu bibliotecznym zapisano też poprzedni numer inwentarzowy - 7377, który umieszczono w zabytku.

Inwentarz składa się z trzydziestu kart o wymiarach ok. 19 x $15 \mathrm{~cm}$, numerowanych współcześnie ołówkiem w prawym górnym rogu strony recto. Manuskrypt został oprawiony w półskórek i tekturę, oprawa jest obecnie nieco zniszczona. $\mathrm{Na}$ przedniej wyklejce, a także na kartach Ir, IIr i $25 \mathrm{v}$ umieszczono czerwoną, prostokątną pieczęć: „BIBLIOTEKA | OO. KARMELITÓW TRZEW. | W KRAKOWIE na PIASKU | Li. 7377". Strony Iv, 2r-4v, 5v, 6v-7v, 9r-IOv, I2v, I5v, I6v-I7v, I9v, 20v, 2IV, 22v, 23v, 26r-27r, 28r-29v i $30 \mathrm{v}$ pozostały niezapisane.

Spis muzykaliów, sporządzony w 1739 r. przez anonimowego pisarza, był zapewne w następnych latach uzupełniany, o czym świadczą późniejsze dopiski dokonane przez dwie inne osoby (w rękopisie występują łącznie trzy dukty pisma)4. Rękopis podzielony został na dziewiętnaście części (I. Missae in folio, 2. Missae in quarto, 3. Litaniae Lavretanae, 4. Litaniae In Folio Lauretanae, 5. Missae in Advent: Rorate, 6. Missae Solemnes in Folio, 7. Missae pro defvnctis, 8. Svffragivm, 9. Motetto De D[omi]nica Vel de Deo, Io. Hymni pro Praecessione \& Motettae De Corpore Christi, II. Motetto de B.V.Ma., I2. Motetto \& Hymni de Spiritu S[anct]o, I3. De S: Apostolis Motettae, 14. De S: Apostolis. Motettae, 15. De Varijs Sanctis Motettae, 16. De Cruce S. Motetto, 17. Część bez tytułu, zawierająca nieszpory i psalmy nieszporne, I8. Offertoria seu Mottetha De Nativitate Christi D[omi]ni, 19. Mottetto de Resurrectione) i zawiera spis około 260 kompozycji. Opisy inwentarzowe prezentują różny stopień szczegółowości: część zapisów zawiera wyłącznie tytuł kompozycji, przy niektórych dopisano obsadę wykonawczą, do rzadkości należą zaś wpisy zawierające nazwisko autora.

3 Por.: Wacław Kolak, Katalog Archiwum oo. Karmelitów w Krakowie „Na Piasku”. I398-1945 (I988), Kraków 1997.

4 Inwentarze sporządzane były co trzy lata na kapitułę prowincjalną. Być może książka inwentarzowa zawiera więc spis muzykaliów, które wykorzystywała kapela karmelitańska w latach czterdziestych XVIII wieku. 
Niektóre tytuły kompozycji zostały wpisane do inwentarza dwukrotnie (zob. nr. 80-I20). Wśród nielicznie zanotowanych nazwisk pojawiają się kompozytorzy polscy lub aktywni na terenie Rzeczpospolitej w I poł. XVIII stulecia, np. Grzegorz Gerwazy Gorczycki, Jacek Szczurowski, Paweł Sieprawski, Józef Kobierkowicz, Szymon Ferdynand Lechleitner, nieznany z imienia Pszczeński, Telesfor Wikliński, a także twórcy środkowoeuropejscy: Johann Valentin Rathgeber, Šimon Brixi i inni.

Inwentarz przynosi informacje o kompozycjach nieodnotowanych w innych źródłach. Zestawiono je w poniższej tabeli:

\begin{tabular}{|l|l|}
\hline Autor & Tytuł \\
\hline Bonus [?] & {$[249]$ Magnificat Solemne a 10 } \\
\hline Breskiewicz [?] & {$[280]$ [Completorium cum Clarinis] Dobre ex Eb } \\
\hline [Šimon] Brixi & {$[190]$ Motetto de BVM] Ad Mariam } \\
\hline Galencio & {$[194]$ Mottetto Sub Tuum Praesidium } \\
\hline Grzegorz Gerwazy Gorczycki & {$[126]$ Requiem ${ }^{5}$} \\
\cline { 2 - 3 } & {$[260]$ Vesperae de D(omi)nica } \\
\hline Józef Kobierkowicz & {$[22]$ Missa ex B } \\
\hline Szymon Ferdynand Lechleitner & {$[247]$ Vespera(e) de Dominica } \\
\hline Pszczeński & {$[25]$ Missa ex B } \\
\hline Johann Valentin Rathgeber & {$[16,94]$ Missa Clar(ini) ex B } \\
{$[24]$ Missa Clar(ini) ex C } \\
{$[70]$ Missa] Ror(ate) } \\
\hline Rother & {$[193]$ Laetamini in D(omi)no } \\
\hline Senary & {$[275]$ [Completorium cum Clarinis] ex Eb. et Dixit } \\
\hline Paweł Sieprawski & {$[20]$ Missa Repelle ex C } \\
\hline Jacek Szczurowski & {$[73]$ Missa de S. Elia ex C } \\
\hline Telesfor Wikliński & {$[71]$ [Missa] Ror(ate) } \\
\hline Wincker / Vinckler & {$[75]$ Missa ex F } \\
& {$[195]$ Diffusa est Gratia ex A } \\
\hline$[123]$ Requiem Choralne na Tenor y Bas \\
{$[258]$ Completorium } \\
{$[33]$ Missa recens ex C } \\
{$[35]$ Missa Oportuna } \\
\hline
\end{tabular}

5 Być może chodzi o Conductus funebris. Katalog kompozycji G.G. Gorczyckiego nie rejestruje „Requiem”, por. Grzegorz Gerwazy Gorczycki. Studia I: katalog tematyczny, red. Zygmunt M. Szweykowski, Kraków I986. 
Dotychczas muzykologom znany był inwentarz kapeli karmelitańskiej z l. I66o-84, rejestrujący tytuły kompozycji z połowy i II poł. XVII w. ${ }^{6}$ Z odnalezionego inwentarza z 1739 r. wynika, że repertuar kapeli zmienił się diametralnie w I poł. XVIII wieku. Dawniejsze kompozycje zapewne nie cieszyły się zainteresowaniem wykonawców ani słuchaczy, dlatego wprowadzono kompozycje nowsze, z lat dwudziestych i trzydziestych XVIII w., utrzymane w innym stylu. Podobny repertuar miała wówczas kapela krakowskich jezuitów (o czym świadczą zachowane w Bibliotece Jagiellońskiej inwentarze z lat trzydziestych i czterdziestych XVIII w.7), a także inne kapele klasztorne w Małopolsce (między innymi cystersów w Mogile, paulinów na Jasnej Górze i jezuitów oraz benedyktynek w Sandomierzu), a także kapela w Rakowie Opatowskim ${ }^{8}$.

Kompozycje odnotowane w osiemnastowiecznym inwentarzu karmelitańskim przeznaczone są na ogół na typową dla tego okresu obsadę a 9 lub a Io, obejmująca cztery głosy wokalne (CATB), dwoje skrzypiec, dwa instrumenty dęte (trąbki clarini lub litui) i basso continuo, realizowane zwykle na organach lub pozytywie9. Czasami rozbudowywano wspomniany typowy skład o wiole, waltornie, oboje i kotty.

Kompozycje wykonywane przez kapelę karmelitańską przeznaczone były na różne okresy liturgiczne i wykonywane podczas wspomnień różnych świętych, w tym karmelitańskich (m.in. proroka Eliasza, św. Alberta Avogadro, św. Szymona Stocka, św. Marii Magdaleny de Pazzi), a także podczas świąt maryjnych, co wynikało z faktu, że kościół na Piasku jest sanktuarium maryjnym.

Niestety dotąd nie udało się dokładnie ustalić, skąd karmelici pozyskiwali repertuar muzyczny. Z inwentarza wynika, że pięć litanii zostało ofiarowanych kapeli karmelitańskiej przez Aleksandra Kazimierza Szembeka (zm. 1756) - wojewodę sieradzkiego ${ }^{\text {Io }}$,

6 Zob.: Tadeusz Maciejewski, „Inwentarz muzykaliów kapeli karmelickiej w Krakowie na Piasku z lat I665-I684", Muzyka 2I (1976) nr 2, s. 77-99.

7 Zob.: Jerzy Kochanowicz, Stownik geograficzny jezuickich burs muzycznych. Materiaty, Kraków 2002, s. 93-II3.

8 Jolanta Byczkowska-Sztaba, Rękopisy i druki muzyczne z XVIII wieku w zbiorach Archiwum Opactwa Cystersów w Krakowie-Mogile. Katalog tematyczny [dokument elektroniczny], Warszawa 2013; Paweł Podejko, Kapela wokalno-instrumentalna paulinów na Jasnej Górze, Kraków 1977; Paweł Podejko, „Katalog tematyczny rękopisów i druków muzycznych kapeli wokalno-instrumentalnej na Jasnej Górze”, Studia Claromontana I2 (1992); Magdalena Walter-Mazur, Figura i fraktem. Kultura muzyczna polskich benedyktynek w XVII i XVIII wieku, Poznań 20I4; Aleksandra Patalas, Dziatalność i repertuar kapeli muzycznej w Rakowie Opatowskim wświetle źródet archiwalnych, w: Muzyka religijna - między epokami i kulturami, red. Krystyna Turek, Bogumiła Mika, t. 2, Katowice 2019, s. 28-44.

9 W kościele karmelitów na Piasku w Krakowie w I poł. XVIII w. na chórze muzycznym znajdowały się organy, zbudowane w l. I7II-I3, a także mały pozytyw szkatulny, zob.: Piotr Matoga, Organy w Bazylice oo. Karmelitów na Piasku w Krakowie, Lublin 2014.

Io Bogata rodzina Szembeków, rezydująca w Krakowie, na Garbarach i w Balicach, regularnie wspierała kościół i klasztor karmelitów, np. w I694 r. karmelici otrzymali wypłatę od P. Krzysztofa Szembeka za woły, w I7I7 r. ks. Krzysztof Szembek, biskup chełmski, ofiarował klasztorowi I75 zł; w I738 r. Antoni Szembek, podkomorzy krakowski, wsparł budowę organów w kościele. Aleksander Kazimierz na Słupowie Szembek, wojewoda sieradzki, starosta kowelski, był stałym patronem konwentu. W 1747 r. wypłacono z kasy konwentu i6 fl. 20 gr „kapeli Jego Mości Pana Wojewody”. 
który pozyskał je ze zbiorów jasnogórskich. Poza tym, sądząc po wpisach inwentarzowych, repertuar mógł pochodzić bezpośrednio z krakowskiej katedry (np. od Grzegorza Gerwazego Gorczyckiego, któremu w l. 1696-99 z kasy klasztornej wypłacano dziesięcinę ze wsi Naremba, należącej do karmelitów ${ }^{\mathrm{II}}$ ) oraz z bursy muzycznej jezuitów.

Należy mieć nadzieję, że dalsze poszukiwania archiwalne w archiwach karmelitów pozwolą na odnalezienie kolejnych cennych zabytków, co doprowadzi do dokładniejszego omówienia kultury muzycznej tego zakonu. Prace zostały zainicjowane.

Tekst źródłowy zaprezentowano w formie transkrypcji przygotowanej według ogólnych zasad edycji typu $\mathrm{B}^{\mathrm{I2}}$ oraz Instrukcji wydawniczej dla źródet historycznych od XVI do potowy XIX wieku ${ }^{13}$. Nie zachowano układu graficznego oryginału. Tekst źródłowy podano w takiej wersji, w jakiej występuje w rękopisie. Tam, gdzie było to konieczne, rozwinięto abrewiacje (oznaczone nawiasem okragłym), a także uzupełniono ewidentne braki (oznaczone nawiasem kwadratowym). Nie rozwijano skrótów oczywistych i powszechnie stosowanych. Miejsca nieczytelne oznaczono kropkami w nawiasach ostrych $\langle\ldots\rangle$. W tekście zachowano oryginalną pisownię wielkich i małych liter. Nie wprowadzono dodatkowej interpunkcji. Na początku każdej pozycji inwentarzowej dodano numerację, umieszczoną w nawiasach kwadratowych, w celu lepszej przejrzystości materiału. Na podstawie dostępnych bibliografii drukowanych oraz baz internetowych (m.in. RISM) starano się ustalić autorów i pełne tytuły dzieł (odnotowując je w przypisie). Niestety w wielu przypadkach identyfikacja była niemożliwa ze względu na skrótowy zapis inwentarza.

\section{TEKST ŹRÓDŁOWY}

Inwentarz Wszystkich rzeczy Które do Choru Figuralnego Kościoła naszego Piaskowego, należą, W Roku I739. należycie spisany

In Nomine Domini Amen

\section{MISSAE IN FOLIO}

[I] No. Imo.

Missa Solemnis cum Clar(ini) ex A

[2] No. IIdo.

Missa S: Stanislai ex G. Clar(ini)

II Archiwum Karmelitów na Piasku w Krakowie, sygn. AKKr 704, Computus perceptarum et expensarum, I68I-1699, s. 753, 794, 856, 902; sygn. AKKr 705, Księga przychodów i rozchodów, 1699-1718, s. 35. Od 1702 r. dziesięcinę wypłacano „XX. Wikariom na Zamek”.

I2 Zasady wydawania tekstów staropolskich. Projekt, opr. Konrad Górski, Jerzy Woronczak, Wrocław I955.

I3 Instrukcja wydawnicza dla źródet historycznych od XVI do potowy XIX wieku, red. Kazimierz Lepszy, Wrocław 1953. 


$\begin{array}{ll}{[3]} & \text { No. IIItio. } \\ {[4]} & \text { No. IVto. } \\ {[5]} & \text { No. Vto. } \\ {[6]} & \text { No. VIto. } \\ {[7]} & \text { No. VIImo. } \\ {[8]} & \text { No. VIIIvo } \\ {[9]} & \text { No IXno. } \\ {[\mathrm{IO}]} & \text { No. Xmo } \\ {[\mathrm{II}]} & \text { No. XImo } \\ {[\mathrm{I} 2]} & \text { No. XIImo }\end{array}$

MISSAE in quarto

[I3] No. Imo.

[I4] No. 2do.

[I5] No. 3tio.

[I6] No. 4to.

[17] No. 5to.

[I8] No. 6to.

[I9] No. $7 \mathrm{mo}$.

[20] No. 8vo.

[2I] No. 9no.

[22] No.romo.

[23] No. IImo.

[24] No. I2mo.

[25] No. I3tio

[26] No. i4to.

[27] No. isto.

[28] No. I6to.

[29] No. $17 \mathrm{mo}$.

[30] No. I8vo.

[3I] No. i9no.

[32] No. $20 \mathrm{mo}$
Missa S: Laurentij ex B. Clar(ini)

Missa S: Floriani ex D. Clar(ini)

Missa S: Antonij ex A. Clar(ini)

Missa cum Tubis ex C. Clar(ini)

Missa S: Gregorij ex Eb. Litui.

Missa S: Matthaei ex C. Clar(ini)

Missa S: Pauli ex F. Clar(ini)

Missa S: Ioannis Sarcandri ex C. Clar(ini)

Missa S: Andreae ex A. Clar(ini)

Missae N(umer)o I3. in Libris 9m scriptae V(a)r(ioru)m Auth(oris)

Missa Solemnis Gedano â 9 m ex C.

Missa Bona â 9 ex A.

Missa optima ex A cum Clar(ini)

Missa Pszc[z]ęnsk[i] Clar(ini) ex B. ${ }^{14}$

Missa Valet ex F Clar(ini)

Missa Cieszynscyana Clar(ini) ex C.

Missa Solemnis â Nomine Iesu. ex A.

Missa Repelle. Aut(hore) Rother ex C. ${ }^{15}$

Missa S. Alberti. Clar(ini) ex Eb.

Missa Kobierkowicz Clar(ini) ex B. ${ }^{16}$

Missa S. Elisei. Clar(ini) ex D.

Missa â Pszc[z]enski Clar(ini) ex C. ${ }^{17}$

Missa Lechleytner Clar(ini) ex B. ${ }^{18}$

Gloria duo: unum ex C: alteru(m) ex B.

Missa S. Benedicti cum Lituis.

Missa S. Michaelis ex G.

Missa S. Gabrielis ex Clar(ini)

Missa S. Eliae ex A. Clar(ini)

Missa S. Iosephi ex D.

Missa Gawronsczyana C.A.B 2 V(iolini) 2 Clar(ini) ex C

I4 Pszczeński - kompozytor, którego nazwisko znane było dotąd wyłącznie z inwentarzy jezuitów krakowskich, spisanych w 1. 1737-4I.

I5 Rother? Kompozytor nieznany.

I6 Józef Kobierkowicz - kompozytor i organista, w latach dwudziestych XVIII w. notowany w źródłach krakowskich, w 1. I73I-35 organista na Jasnej Górze. Niewykluczone, że chodzi o mszę ku czci św. Stanisława (por. nr Ioo).

I7 Pszczeński, zob. wyżej.

I8 Ferdinand Simon Lechleitner - kompozytor środkowoeuropejski, aktywny w XVIII w., przez jakiś czas związany z dworem Lubomirskich, zob.: Dominika Grabiec, „Offertoria Szymona Ferdynanda Lechleitnera ze zbiorów muzykaliów Biblioteki Wyższego Seminarium Duchownego w Sandomierzu”, Przegląd Muzykologiczny 6 (2006), s. 17-59. Katalog utworów Lechleitnera, sporządzony przez Dominikę Grabiec i opublikowany we wspomnianym artykule, nie rejestruje Mszy ex $B$. Na temat twórczości Lechleitnera zob. też: Dominika Grabiec, „Ave Maris Stella» Szymona Ferdynanda Lechleitnera ze zbioru muzykaliów po klasztorze pijarów w Podolińcu”, Muzyka 57 (2012) nr 3, s. 23I-242. 


$\begin{array}{ll}{[33]} & \text { No. 2Imo } \\ {[34]} & \text { No. 22do } \\ {[35]} & \text { No. 23tio } \\ & \\ {[36]} & \text { No. 24to } \\ {[37]} & \text { No. 25to } \\ {[38]} & \text { No. 26to. } \\ {[39]} & \text { No. 27mo } \\ {[40]} & \text { No. 28vo. } \\ {[4 \mathrm{I}]} & \text { No. 29no } \\ {[42]} & \text { No. 30. }\end{array}$

Missa recens Wincker ex C. Clar(ini) ${ }^{19}$

Missa Italiana S. Cyrilli ex A Clar(ini)

M(iss)a Oportuna Vinckler C. A. B. obligato. V(iolini) Clar(ini)

C: ad libitum $\operatorname{Org}(\text { ano) oblig(ato })^{20}$

Missa Scapularis C.B. Org(ano) obligato. ${ }^{21}$

Missa S. Stephani. brevis valet.

Missa S. Spiritus.

Missa S. Pauli.

Missa Pax cum Lituis. Chorowa

Mis(sa) S. Hieronymi

Laetare: Introitus in D(omi)nica 3tia Quadrage(sim)ae

\section{LITANIAE LAVRETANAE.}

[43] Litanię N(umer)o. Imo. Mater Divine gratiae ex C. | C. A. T. B. 2 Viol(ini) 2. Clar(ini) Alto

[44] No 2. Lit(ania) Mater Creatoris a ro ex Eb.

[45] No. 3. Lit(ania) Regina Angelorum, et omnium Sancto(rum) | Sunt aliquae cum Tubis, aliae cu(m) Valtornis Hoboi: | Videat' in Libro Litaniarum

[46] No. 4to. Virgo fidelis. | [uzupełnienie inną ręką:] Virgo prudentissima | Virgo Veneranda V. p(er) dicanda

[47] No. 5to. Virgo clemens. | [uzupełnienie inną ręką:] Vir(go) Clemens Vir(go) Fidelis | Speculum Justitiae

[48] No. 6to. Mater \& decor Carmeli â ıo. | A. C. T. B. 2 Viol(ini) 2. Clar(ini) ex

[49] No. 7 mo Mater Amabilis.

[50] No. 8vo Mater Admirabilis. | [dopisek inną ręką:] Creatoris

[5I] No. 9no. Mater Salvatoris.

[52] No. Iomo Virgo prudentissima

[53] No. IImo. Virgo Veneranda

[54] No. I2mo. Virgo praedicanda.

[55] No. iztio. Speculum justitiae.

[56] No. I4to. Sedes Sapienti(a)e

[57] No. I5to. Causa nostrae laetitiae.

[58] No. I6to. Vas Spirituale.

[59] No. I7mo. Vas Honorabile.

LITANIAE In Folio Lauretanae de Claro Monte transmissae ac donatae Ill(ustri)s(si)mo D(omino) Szembek Palatino Siradien(sis) Capitaneo Beccen(sis) etc. etc.: ac tandem ab eode(m) Ill(ustris)s(i)mo oblatae ad usum et praecticand. Pro Choro F(ratrum)m Carm(elitarum) in Arenis Crac(oviensis)

I9 Winckler? Vincler? Kompozytor nieznany.

20 Ibid.

2I Być może chodzi o Missa X. S. Scapularis B. V. Mariae Johanna Valentina Rathgebera, opublikowaną w druku pt. Decas Mariano-Musica. Hoc est: X. Missae solennes diductiores minusque solennes breviores non tam pro Festivitatibus B. V. Mariae, quam per annum universim producensis..., Augsburg I730; zob. RISM ID no.: 408000049 . 


$\begin{array}{llr}\text { [6o] } & \text { No. I. } & \text { Lit(aniae) ex B: CA.T.B. 2 V(iolini) 2 Cl(arini) ex B.: Organ(o) } \\ \text { [6I] } & \text { No II. } & \text { Lit(aniae) ex F. CA.T.B. 2. V(iolini) 2. Cl(arini) Organo: } \\ {[62]} & \text { No III. } & \text { Lit(aniae) ex C. CA.T.B. 2 V(iolini) 2. Cl(arini) Organ(o) } \\ {[63]} & \text { No. IV. } & \text { Lit(aniae) ex C. CA.T.B. 2. V(iolini) 2. Cl(arini) Organo. } \\ {[64]} & \text { No. V. } & \text { Lit(aniae) ex C. CA.T.B. 2. V(iolini) 2 Cl(arini) Organo. } \\ {[65]} & & \text { Lijtaniae de Nomine Jesu ex B. C.A.T.B. V(iolini) 2 H(obois) 2. Org(ano) } \\ {[66]} & & \text { Lijtaniae de Nomine. Jesu ex Dis. C.A.T.B. V(iolini) 2. H(obois) 2 Or(gano) } \\ {[67]} & & \text { Lijtaniae de Nomine. Jesu ex G. C.A.T.B. V(iolini) 2 C(larini) 2 Or(gano) } \\ {[68]} & & \text { Lijtaniae de S. Joseph(o) C(anti) 2. B(asso) V(iolini) 2. H(obois) 2. Org(ano) }\end{array}$

2

Missae in Advent: Rorate.

[69] No. I: Ror(ate) antiq(u)m ex Choro cum Cantilenis

[70] No. 2: Ror(ate) Authore Pszc[z]enski. ${ }^{22}$

[7I] No. 3: Ror(ate) Aut(hore) R(everendo) P(at)re: Sieprawski Ord(inis) S(ancti) Bened(icti) ${ }^{23}$

[poniżej dopisane inną ręką tytuły różnych mszy:]

[72] N[o] I Missa de S. Joan(ne) Nepom(uceno) C.A.TB. V(iolini) 2 C(larini) 2 Org(ano)

[73] N[o] 2. Missa de S. Elia ex C. CA.T.B. Viol(ini) 2 C(larini) 2 Aut(hore) Senary ${ }^{24}$

[74] No 3. Missa de S. Alberto ex D. CAT.B. 2 Viol(ini) <...> CH. 2. C(larini) 3 | Viola Alto \& Tympano con Org(ano)

[75] No 4. Missa ex F. C.A.T.B. Viol(ini) 2 C(larini) 2. Org(ano) Aut(hore) Szczurowski25

[76] No 5. Missa ex C. C.A.T.B. Viol(ini) 2. Clar(ini) 2. Org(ano)

[77] No 6. Missa de S. Valentino C. A. T. B. V(iolini) 2. C(larini) 2. Lit(ui) 2. Org(ano)

[78] No 7. Missa de S. Francisco. TB. V(iolini) 2. Lit(ui) 2. Org(ano)

[79] [No 8] Missa de S. Simone Stock. A. T. B. V(iolini) 2. Lit(ui) 2. Org(ano)

Missae: Solemnes: in Folio
$[8 \mathrm{O}=\mathrm{I}] \quad$ No. Imo
Cum Cl(arini) ex A: C.AT.B 2 V(iolini) 2 C(larini). Organo.
$[8 \mathrm{I}=2] \quad$ No. 2 do
S. Stanislai ex C: CAT.B. 2 V(iolini) 2 Cl(arini) $\operatorname{Org}($ ano $)$
$[82=3] \quad$ No. 3tio.
S. Laurentij ex B: CATB. 2 V(iolini) 2 Cl(arini) Organo
$[83=4] \quad$ No. 4 to.
S. Floriani ex D: CAT.B 2 V(iolini) 2. $\mathrm{Cl}$ (arini) Organ(o)
$[84=5] \quad$ No. 5to.
S. Antonij ex A: CAT.B. 2 V(iolini) 2 Cl(arini) Organo
$[85=6$ ?] No. 6to.
[pozostawione puste miejsce]
$[86=7] \quad$ No. $7 \mathrm{mo}$
S: Gregorij ex Eb: CATB. 2 V(iolini) 2 Cl(arini) Organo
$[87=8] \quad$ No. 8 vo.
S. Matthaei ex. C: \& ut supra.

22 Pszczeński, zob. wyżej.

23 Paweł Sieprawski OSB, kompozytor żyjący na przełomie XVII i XVIII w., wywodzący się z Zakonu Benedyktynów, związany z kolegiatą w Sandomierzu. W dotychczas znanych źródłach nie był notowany jako zakonnik, zob.: Maciej Jochymczyk, „Wstęp”, w: Paweł Sieprawski, Justus germinavit. Plaudite sidera. Regina caeli, wyd. Maciej Jochymczyk, Kraków 2012 (= Sub Sole Sarmatiae I4), s. 5-13.

24 Senary? Kompozytor nieznany.

25 Jacek Szczurowski SJ (I716?-po 1773) - kompozytor, uczeń jezuickiej bursy muzycznej w Krakowie w 1. I735-37, następnie muzyk, kapelmistrz i nauczyciel w bursach muzycznych w Kaliszu, Gdańsku, Krakowie, Jarosławiu, Grudziądzu, Poznaniu, Wałczu, zob.: Barbara Przybyszewska-Jarmińska, „Szczurowski Jacek”, w: Encyklopedia Muzyczna PWM, red. Elżbieta Dziębowska, t. Io, Kraków 2007, s. $236-237$. 


\begin{tabular}{|c|c|c|}
\hline$[88=9]$ & No. 9no. & S. Pauli ex F: etc: ut supra \\
\hline$[89=10]$ & No. Iomo. & S. Ioannis Sarcandri. ex. etc: ut supra \\
\hline$[90=\mathrm{II}]$ & No. IImo. & S. Andreae. ex A: \&c ut supra \\
\hline \multicolumn{3}{|c|}{ Missae in quarto: } \\
\hline [9I $=\mathrm{I} 3]$ & No. I. & M(issa) Solemnis Gedano: ex C. \&c ut in alijs \\
\hline [92 =34] & No II. & M(issa) S. Cyrilli Italiana. ex A: \&c ut sup(ra) \\
\hline$[93=15]$ & No. III. & $\mathrm{M}$ (issa) optima ex A: \&c ut in alijs Missae \\
\hline [94 =I6] & No. IV. & M(issa) Pszczenski ex B: \&c: ut supra. ${ }^{26}$ \\
\hline$[95=17]$ & No. V. & M(issa) Valet ex F. etc: ut supra. \\
\hline [96 = 18$]$ & No. VI. & Cieszynscyna ex C: etc: ut supra in alijs M(i)s(sa). \\
\hline [97 =19] & No. VII. & Missa Solemnis a Nomine Iesu. \\
\hline [98 =20] & No. VIII. & M(issa) a Repelle: ex C: \&c ut supra \\
\hline$[99=2 \mathrm{I}]$ & No. IX. & $\mathrm{M}$ (issa) S. Alberti. ex Eb. \&c ut in alijs $\mathrm{M}$ (issa) \\
\hline$[100=22 ?$ & & No. X. M(issa) S: Stanislai. \\
\hline [IOI =23] & No. XI. & M(issa) S. Eliae ex D. etc. \\
\hline [1O2 $=24]$ & ] No. XII. & M(issa) S. Boni ex C: \\
\hline [103 =?] & No. XIII. & M(issa) S. Primi ex A: \\
\hline [IO4 $=26$ & & No. XIV. Gloria duo ex B. \\
\hline [105 =27] & No. XV. & M(issa) S. Benedicti. ex D. \\
\hline [106 =28] & No. XVI. & M(issa) S. Michaelis. ex G. \\
\hline [107 =29] & ] No. XVII. & M(issa) S. Gabrielis ex C. \\
\hline [108 =30] & No. XVIII. & M(issa) S. Elisei ex A. \\
\hline [109 $=3 \mathrm{I}]$ & No. XIX. & M(issa) S. Ioseph(i) ex D. \\
\hline [IIO =32] & No. XX. & M(issa) Gawrońsczyana ex C. \\
\hline$[\mathrm{III}=36]$ & No. XXI. & M(issa) Scapularis in Arenis oblata. \\
\hline$[\mathrm{II} 2=35$ ?] & No. XXII. & M(issa) Scapularis: In tempore oportuno. \\
\hline$[\mathrm{II} 3=37]$ & No. XXIII. & M(issa) S. Stephani. \\
\hline [II4 =?] & No. XXIV. & M(issa) In tempore oportuno. \\
\hline$[\mathrm{II} 5=38]$ & No. XXV. & M(issa) S. Spiritus. \\
\hline [II6 =?] & No. XXVI. & M(issa) S. Petri \\
\hline$[$ II7 = 39] & No. XXVII. & M(issa) S. Pauli a ıo. \\
\hline [II8 $=4 \mathrm{O}]$ & No. XXVIII. & M(issa) Pax cum lituis. \\
\hline$[\mathrm{II} 9=4 \mathrm{I}]$ & No. XXIX. & M(issa) S. Hieronymi \\
\hline$[\mathrm{I} 2 \mathrm{O}=42]$ & No. XXX. & Laetare pro Quadragesima. \\
\hline
\end{tabular}

\section{MISSAE PRO DEFVNCTIS.}

[I2I] Requiem dictum Zamkowe, na cztery głosy: alias | na dwa chory.

[I22] Requiem Trzemieliczowe z Lublina.

[I23] Requiem Choralne na Tenor y Bas [dopisek inną ręką:] Auth(ore) P(at)re Thelesph(oro) $\mathrm{C}(\text { armelita })^{27}$

26 Pszczeński, zob. wyżej.

27 O. Telesfor Wikliński OCarm. - organista i kompozytor, ur. ok. I688 r. w Końskich, na chrzcie otrzymał imię Grzegorz. Do Zakonu Karmelitów wstąpił 4 I 1707 r. (Archiwum Karmelitów na Piasku w Krakowie, sygn. AKKr I28, Księga przyjętych do nowicjatu w klasztorze karmelitów w Krakowie na 
[124] Requiem breve in Capella Scapulari practicandu(m)

[I25] Item alterum tale.

[126] Requiem X(iędza) Kapelle M(a)g(ist)ra. X(iędza) Gorczyckiego ${ }^{28}$.

[I27-I28] Kondukt na Cztery głosy Choralne: y drugi takowysz ${ }^{29}$

\section{SVFFRAGIVM}

[I29] Pro Animabus Defunctis â tre Voc(i) | 2. CC: B. 2 Viol(ini) \& 2. Hobois. r Clar(ino) Organ(o)

Motetto De D(omi)nica Vel de Deo.

$\begin{array}{lll}\text { [130] } & \text { No. I. } & \text { Laetare exulta. â Io. CATB 2 Viol(ini) 2. Clar(ini) } \\ {[\mathrm{I} 3 \mathrm{I}]} & \text { No. } 2 . & \text { Huc populi: â Capella. } \\ {[\mathrm{I} 32]} & \text { No. 3. } & \text { Laetentur Caeli: } \\ {[\mathrm{I} 33]} & \text { No. } 4 . & \text { Resonent Organa: vel de Sanctis. } \\ {[\mathrm{I} 34]} & \text { No. } 5 . & \text { Benedictus sit Deus, â Io C A } \\ {[\mathrm{I} 35]} & \text { No. } 6 . & \text { Vivit Dominus, cu(m) Voc. ut Supra. } \\ {[\mathrm{I} 36]} & \text { No. } 7 . & \text { Te Sanctum Dominum in Folio. } \\ {[\mathrm{I} 37]} & \text { No. } 8 . & \text { Diligam te Domine. S. B. Ibidem } \\ {[\mathrm{I} 38]} & \text { No. } 9 . & \text { Dextera D(omi)ni Solo Alto 2 Viol(ini) Organ(o) } \\ {[\mathrm{I} 39]} & \text { No. IO. } & \text { Quinq(ue) Motett(o) in Folio. }\end{array}$

Mot(etti) 6. De Dominicis Vel de Deo.

[I40] No. Imo. Iubilate. \&

[I4I] No. 2do. Perfice gressus meos.

[I42] No. 3tio. Laudate D(omi)num omnes gentes.

[143] No. 4to. Benedicite gentes.

[I44] No. 5to. Gloria \& honore de Martyr.

[I45] No. 6to. Cantemus Domino.

[I46] No. 7 Cofitebuntur tibi.

Hymni pro Praecessione \& Motettae | De Corpore Christi

$\begin{array}{lll}\text { [I47] } & \text { No. Imo. } & \text { Lauda Syon Salvatorem } \\ \text { [I48] } & \text { No. 2do } & \text { Iesu dulcis memoria. } \\ \text { [149] } & \text { No. 3tio. } & \text { Iesu latescens }\end{array}$

Iydem hymni sunt in altero sexter:

Ibidem Mot(etti) quinq(ue) de Corpore (Chri)sti Item VI:
[I50] No. I.
O Dies beata: C.AT.B. 2 V(iolini) 2 Lituis
[I5I] No. 2.
Venite Angeli Concerto 2 Can(ti) Bas(so)
[152] No. 3 .
Gustate libate Conc(erto) S. Alto 2 V(iolini). O(rgano)
[I53] de Mot: No. 4. Sacerdotes Domini. Imo

\footnotetext{
Piasku, I57I-1754, s. I65). Notowany w rachunkach na Piasku w l. I7IO-23. Zmarł po 26 VIII I725 r., zob. T. Chrzanowski, T. Maciejewski, Graduat karmelitański, s. 82, zob. także: Archiwum Karmelitów na Piasku w Krakowie, sygn. AKKr I30, Cathalogus professorum, I572-1754, s. 34I.

28 Grzegorz Gerwazy Gorczycki (1665/67-1734) - kompozytor, kapelmistrz zespołu wokalno-instrumentalnego katedry krakowskiej w l. 1698-1734.

29 Być może chodzi o Conductus funebris Grzegorza Gerwazego Gorczyckiego.
} 


$\begin{array}{ll}\text { [I54] } & \text { No. } 2 . \\ {[\mathrm{I} 55]} & \text { No. } 3 . \\ {[\mathrm{I} 56]} & \text { No. } 4 . \\ {[\mathrm{I} 57]} & {[\text { inną ręką: }} \\ {[\mathrm{I} 58-\mathrm{I} 59]} & \end{array}$

MOTETTO de B.V. Ma.

[160] No. I

[I6I] No. 2.

[162] No. 3 .

[163] No. 4.

[I64] No. 5.

[165] No. 6.

[I66] No. 7.

[167] No. 8 .

[I68] No.9.

[169] No. IO.

[I70] No. II.

[I7I] No. I2.

[I72] No. I3.

[I73] No. I4.

[174] No. I5.

[I75] No. I6.

[I76] No. I7.

[I77] No. I8.

[I78] No. I9.

[I79] No. 20 .

[I80] No. 2I.

[I8I] No. 22.

[182] No. 23 .

[183] No. 24.

[dalej inną ręką:]

[I84] No. 25.

[I85] No. 26.

[I86]

[I87]

[I88]

[I89]

[190] No. 27.

[I9I]

[192]
O Salutaris hostia.

O quam svavis es $\mathrm{D}$ (omi)ne

Laudetur S(anctis)s(i)m(um) Sacramentum.

Sub specie Panis C(anto) solo Viol(ini) 2. Org(ano)

Hymni 2. Im(us) Verbum suprum. 2d(us) O salutaris | C.A.T.B.

Viol(ini) 1. 2. Clar(ini) 2. Org(ano)

Benedicta \& venerabilis es.

Ad Mariam.

Maria gustum sentio.

Tota pulchra es.

Salve Virgo Sapiens.

Ite Sodales.

Ave ex omnipotentia

Eia rosa.

Gaude Dei genitrix

Virgo Dei genitrix

Omni die

Ave maris stella.

Gaudeamus \& laetemur.

Maria gustum sentio

Ave maris stella.

Ad Mariam cum tribularer.

Ave Maria gratia plena.

Omni die dic Mariae.

Sub tuum praesidium.

Pulchra tota sine nota.

$\mathrm{O}$ mater amoris.

Ave Virgo singularis.

Nubes candidae sulgurate.

Ad te Maria.

Omni die ex D. C.A.T.B. Viol(ini) 2. C(larini) 2. Org(ano)

Motetto 5. Ima Tu Gloria Jerusalem CATB. Viol(ini) 2. Org(ano)

II. O Maria Cali gaudium C.A.T.B. Viol(ini) 2. Org(ano)

III. Eja Matrix CATB Viol(ini) 2. Clar(ino) solo. Org(ano)

IV. Maria Mater Gra(ti)ae CATB Viol(ini) 2. Org(ano)

V. Ave Maris Stella. C(anto) solo Viol(ini) 2. Org(ano)

Ad Mariam C.A.T.B. Viol(ini) 2. C(larini) 2. Org(ano) A Brixio ${ }^{30}$. Speciosa facta es CATB. Viol(ini) 2. C(larini) 2. Org(ano)

Aria 2. Ima Filiae Jerusalem.

30 Prawdopodobnie chodzi o Šimona Brixiego (1693-1735), kompozytora i organistę z Pragi. Na terenie Rzeczpospolitej bardziej rozpowszechniona była twórczość jego syna, Františka Xaverego, który urodził się dopiero w 1732 r., zob.: Alina Nowak-Romanowicz, „Brixi”, w: Encyklopedia muzyczna PWM, red. Elżbieta Dziębowska, t. I, Kraków 1979, s. 422-423. 
[193]

[194]

[195] No. 29.

[196] No. 30 .

[197] No. 3I.

[198] No. 32 .

[199] No. 33 .

[200] No. 34.

[20I] No. 35.

[202] No. 36 .

[203] No. 37 .

[204] No. 38 .

[205] No. 39 .

[206] No. 40.

[207] No. 4I 2da Laetamini in $\mathrm{D}$ (omi)no Basso solo Viol(ini) 2. Clar(ini) 2 A Pszczenski ${ }^{31}$

Itt(em) Mottetto Sub Tuum Praesidium CATB Viol(ini) 2. Cornu(m)

2. $\operatorname{Org}$ (ano) Auth(orem) Galencio ${ }^{32}$

Diffusa est Gratia C.A.T.B. Viol(ini) 2. C(larini) 2. ex A et Org(ano)

Auth(ore) Szczurowski S.J:33

Ave Maria C.A.T.B. 2. Viol(ini) Cornu 2 ex Dis $\operatorname{Org}(\operatorname{ano})$

Regina Caeli Italiano C.A.T.B. Viol(ini) 2 Org(ano)

Aria I. Ave Stella C(anto) solo. Viol(ini) 2. Alto Viola Org(ano)

Aria II. Ave Maria C(anto) solo. Viol(ini) 2. Alto Viol(a) Org(ano)

Aria III Ave Virgo Sing. C(anto) solo Viol(ini) 2. Alto. Viol(a) Org(ano)

Aria IV. Salve o Virgo Florens C(anto) Solo Viol(ini) 2. Alto

Viol(a) Org(ano)

Aria V. Maria Gustum sentio C(anto) solo. Viol(ini) 2. Alto Viol(a)

Org(ano)

Aria VI Huc huc fideles A(lto) solo. Viol(ini) 2. Org(ano)

Aria VII. Nigra sum sed $<\ldots .>$ C(anto) solo Viol(ini) 2 Alto Viol(a)

Org(ano)

Aria VIII. Ad te cor volae. C(anto) solo Viol(ino) Solo. Org(ano)

Aria IX. Omni dies C(anto) solo. Viol(ini) 2 Org(ano)

[skreślone] Mottetto. Ego Mater. C. A. T. B. Viol(ini) 2. Org(ano)

Motetto \& Hymni de Spiritu S(anct)o

$\begin{array}{lll}{[208]} & \text { No. I. } & \text { Hymnus. Beata nobis gaudia. } \\ {[209]} & \text { No. } 2 . & \text { Spiritus Domini replevit. } \\ {[2 \mathrm{IO}]} & \text { No. } 3 . & \text { Cum complerentur dies Pentecostes. } \\ {[2 \mathrm{II}]} & \text { No. } 4 . & \text { Confirma hoc Deus } \\ {[2 \mathrm{I} 2]} & \text { No. } 5 . & \text { Veni S(ancte) Spiritus No. 4or Veni Creator }\end{array}$

De S: Apostolis. Motettae.

$\begin{array}{lll}{[2 \mathrm{I} 3]} & \text { No. I. } & \text { Exultet caelum laudibus. } \\ {[2 \mathrm{I} 4]} & \text { No. II. } & \text { In omnem terram. } \\ {[2 \mathrm{I}]} & \text { No. III. } & \text { Isti sunt viventes in Carne. } \\ {[2 \mathrm{I} 6]} & \text { No. IV. } & \text { Sancti amici Dei. } \\ {[2 \mathrm{I}]} & \text { No. V. } & \text { Cives Apostolorum. } \\ {[2 \mathrm{I} 8]} & \text { No. VI. } & \text { Ecclesiarum Principes. } \\ {[219]} & \text { No. VII. } & \text { Bonum Certamen. } \\ {[220]} & \text { No. VIII. } & \text { De S. Andrea Apostolo. Mott(etto) } \\ {[22 \mathrm{I}]} & \text { No. IX. } & \text { Isti sunt sancti. } \\ {[222]} & \text { No. X. } & \text { Isti sunt viri. } \\ {[223]} & \text { No. XI. } & \text { Item. Bonum certamen. }\end{array}$

3I Pszczeński, zob. wyżej.

32 Galencio? Kompozytor nieznany.

33 Jacek Szczurowski SJ, zob. wyżej. 
De Varijs Sanctis Motettae.
[224] No. I.
De S: Patre Nostro Elia.
[225] No. 2.
De S: Alberto O.N. Conf: cum Clar(ini) \& Tympany
[226] No. 3 .
Idem Mott(etto) \& de alijs Servit San(cto) atq(ue) Patriarchis
[227] No. 4 .
De S: Simone Stochio. Conf(essor)
[228] No. 5.
De S: Bonaventura(e) Doct(oris) Eccl(esiae) \& alijs Doct:
[229] No. 6.
[230] No. 7 .
De S: Franco O.N. Ibide(m) de S(ancti)S(si)mae Trinitate.
[23I] No. 8.
De quocunquo $S$ (pirit)o vel de Angelis Huc caelestes.
[232] No.9.
De Conf: Iustum deduxit.
[233] No. Iо.
Item: In Virtute tua.
[234] No. II.
[235] No. I2.
Iustus ut palma florebit.
De Pascha. Haec est dies.
[236] No. 13.
[237] No. I4.
Mulierem fortem.
[238] No. 15 .
Magdalena Virgo. [inną ręką:] de S. Magdal(ena) Pazzis.
Hymn(us): Ave Virgo Florentina.
[239] No. I6.
Concerto de Nativitate D(omine) I(esu) (Chri)sti
[240] No. 17.
[24I] No. I8.
Mottetta cum 3b(us) Arijs ex D. CATB 2. Viol(ini) Org(ano)
En gratulemur. CATB 2Viol(ini) Clar(ini) 2 Org(ano)
Eia voces. C(anto) solo. Viol(ino) Solo Concerto Org(ani) 2.

De Cruce S. Motetto.
[242] No. I.
[243] No. II.
Signum Crucis mirabile
Salve Crux sancta.
[244] No. III.
Graduale de Cr(ucis) Super omnia ligna Cedror(um)
[245] No. IV.
Hymnus. Vexilla Crucis prodeunt.
[246] No. V.
Mott(etto) O crux ave Spes unica.
[247] In folio No. 8. Vesperae De Dominica: C.A.T.B. 2 Viol(ini) 2. Clar(ini) Organo.
Aut(hore) Kobierkowicz ${ }^{34}$.
[248] In folio Dixit D(omi)nus C. A. T. B. 2. Viol(ini) Org(ano)
[249] In folio No. 7. Magnificat Solemne. â ıo: CA.T.B 2. Viol(ini) 3 Clar(ini) Org(ano) et Tympano. Aut(hore) Bonus ${ }^{35}$.
[250] In quarto No. I: Vesperae Solemnes Dixit: Laudate D.: Lauda anima mea: Laudate D(ominu)m quoniam bonus, Lauda Hierusalem: CATB. Viol(ini) 2 Clar(ini) Org(ano) Fagotto.
$[25 \mathrm{I}]$ No: I. Domine ad adjuvandu(m) ex C: CATB 2 V(iolini) 2 Cl(arini) Or(gano)
[252] Ibidem
Confitebor: Beatus vir: Ibidem. Psalmi duo Beati omnes. et Lauda Hierusale(m) C.A.T.B. 2 Viol(ini) Org(ano) Viola
[253] No. VI. Vesperae Solemnes. â Io: C.A.T.B. 2 V(iolini) 2. Cl(arini) Or(gano) Viol(a) Aut(hore) R(everendo) P(ater) Rathgeber. Ord(inis) S(ancti) Bened(icti) ${ }^{36}$ :

34 Józef Kobierkowicz, zob. wyżej.

35 Bonus? Kompozytor nieznany.

36 Johann Valentin Rathgeber OSB (I682-I750) - niemiecki kompozytor i organista, zob.: Marcin Konik, „Muzyka religijna Johanna Valentina Rathgebera (1682-1750) w świetle źródeł polskich”, Muzyka 53 (2008) nr 3, s. 3I-43. 


$\begin{array}{ll}{[254]} & \text { No. IV. } \\ {[255]} & \text { No. II: } \\ {[256]} & \text { No. 2. } \\ {[257]} & \text { No. IX. } \\ {[258]} & \text { No. X. } \\ {[259]} & \text { No. 3. } \\ {[260]} & \text { Item }\end{array}$

[26I] No. VII.

[262] No. V.

[263] No. I.

[264] In 3 Ps.

[265] No. I.

[266] Item No. II.

[267] I.

[268] II.

[269] III.

[270] I(te)m 4 Psal.

[27I] Psalm(us)

[272] Item:

[273] 7. Psalm(us)

[274] 4to 8vo
Vesperae de Dominica. D(omi)ne ad adjuvan(dum). Dixit: Confitebor: Beatus vir: Laudate pueri: Laudate $\mathrm{D}$ (ominu)m

Om[n] es gentes: In exitu(m) Credidi: CATB 2 V(iolini) 2 Lituis. Org(ano)

Vesperae Cathedrales de Beata

Vesperae breves: CAT.B. 2 V(iolini) 2 Cl(arini) Viola Alt(a) Or(gano)

Completoriu(m) CA.T.B. 2 V(iolini) 2. Cl(arini) Or(agno) Viol(a)

| Auth(ore) P(at)re Thelesphoro Carm(elita) ${ }^{37}$.

Vesperae Solem de Beata ex Dis: CATB. 2 V(iolini) 2 Cornu.

$\mathrm{O}$ (rgano)

Vesperae de $\mathrm{D}$ (omi)nica A(dmodum) R(everendus) P(ater) Gorczycki $^{38}$ Sine Clarinis CATB 2 V(iolini) Or(gano) D(ixit Dominus) $\mathrm{C}$ (onfitebor) $\mathrm{B}$ (eatus vir) L(audate pueri) L(audate) $\mathrm{D}$ (ominu) $\mathrm{m}$ $o(\mathrm{mn})$ es gent(es) Magnif(icat)

Vesperae De Beata et De D(omi)nica C.ATB 2 V(iolini) 2 Clar(ini) Vesporae [sic!] De Dominica. CATB. 2 V(iolini) 2 Cl(arini) Org(ano) (Vio)Le:

$\mathrm{D}$ (omi)ne ad adjuvandu(m) 2. C(anti) $\mathrm{ATB} 2 \mathrm{~V}$ (iolini) $2 \mathrm{Cl}$ (arini) Org(ano)

$\mathrm{D}$ (omi)ne ad adjuv(andum). Dixit $\mathrm{D}$ (omi)n(us) Laudate pueri:

I. Dixit tres I 2 C(anti) A.T.B. 2 V(iolini) Org(ano) Viol(a). 2 dum

CATB 2 V(iolini) 2 Lituis ex Eb, 3tiu(m) CATB 2 V(iolini) 2 $\mathrm{Cl}$ (arini) ex A:

Laudate $\mathrm{D}$ (omi)num quoniam bonus est psalmus | C.A T.B 2 V(iolini) 2. Clar(ini) Org(ano) Fagotto

Laudate $\mathrm{D}$ (ominu)m q(uonia)m bonus est psalmus Voces aedem

Tres Psalmi Lauda Ierusalem CATB 2 V(iolini) 2 Cl(arini)

2. Laetatus sum. Voces aedem

3. Eauda Hierusatem Bassani ${ }^{39}$ Italiano Veed. <...>

I. De profundis. 2. Memento D(omi)ne. | 3. Eripe me de Martyr. |

4. In exitu Israel de $\mathrm{D}$ (omi)nica cum Lituis.

Laudate Pueri D(omi)num CATB 2 V(iolini) 2 Cl(arini) ex C:

Laudate Puer(i) D(ominum) ex C:

I. In exitu: 2. Credidi Ibid(em) 3. In Convertendo ibid(em) 4 . Ibidem D(omi)ne probasti me. 5. Ibid(em) De profundis | 6. Memento D(omi)ne: 7. Confitebor de Angelis.

Quatuor Psalmi Sine Clar(inis) I. D(omi)ne probasti me, | 2. De profundis. 3. Memento $\mathrm{D}(\mathrm{omi})$ ne. 4. In exitu

Item Completorium cum Clarinis.

Psalmi seorsivi Magnificat.

[275] No. I. ex Eb. et Dixit CAT.B. 2 V(iolini) 2 Cl(arini) A. Ps(z)czen(ski) $4^{40}$

37 Telesfor Wikliński O Carm., zob. wyżej.

38 Grzegorz Gerwazy Gorczycki, zob. wyżej.

39 Tytuł utworu i nazwisko Bassani skreślone.

40 Pszczeński, zob. wyżej. 


\begin{tabular}{|c|c|c|}
\hline [276] & No. II. & $\begin{array}{l}\text { Mag(nificat) Solemne â ı2. CATB } 2 \text { V(iolini) } 2 \text { Cl(arini) Viol(a) } \\
\text { Tymp(ano) }\end{array}$ \\
\hline [277] & 2. & $\begin{array}{l}\text { Mag(nificat) ab II. CATB } 2 \text { V(iolini) } 2 \text { Cl(arini) con Viol(a) } \\
\text { Tymp(ano) }\end{array}$ \\
\hline [278] & No. III & $\begin{array}{l}\text { Solemne a I2. CATB. } 2 \text { V(iolini) } 2 \text { Cl(arini) Org(ano) Tymp(ano) } \\
\text { Viol(a) }\end{array}$ \\
\hline & No. IV & Solemne CATB 2 V(iolini) 2. Cornu: Org(ano) Viol(a) \\
\hline & No: VI & Dobre: a Breskiewicz ${ }^{41}$ Obl: CATB 2 Viol(ini) 2. Clar(ini) ex Eb. \\
\hline & No: V & a 9. CATB 2 V(iolini) 2 Clar(ini) ab libitu(m) O(rgano) V(iola). \\
\hline & No: VII. & Ex F a 4. Voc(um) et 2 V(iolini) Org(ano) et Viol(a) \\
\hline$[2825 \cdot 3$ & No: VIII. & Solo Basso et V(iolini) 2. ac Clar(ini) 2 ex A. \\
\hline
\end{tabular}

OFFERTORIA Seu MOTTETHA De Nativitate Christi D(omi)ni

$\begin{array}{lll}{[284]} & \text { No. I } & \text { Offertorium in Ima Missa ex G cum Clarin(i) | Laetentur Caeli } \\ {[285]} & \text { No. } 2 . & \text { Offertorium p(er) 2da Missa ex A De(us) firmavit cum Clar(ini) } \\ {[286]} & \text { No. 3. } & \text { Offertorium p(er) 3tia Missa ex C Tui sunt Caeli cum C(larini) } \\ {[287]} & \text { No. } 4 . & \text { Mottetto Nos Coloni. C.A.T.B. Viol(ini) 2. Org(ano) } \\ {[288]} & \text { No. 5. } & \text { Mottetto Huc Pastorculi C.A.T.B. Viol(ini) 2. C(larini) 2. Org(ano) } \\ {[289]} & \text { No. 6. } & \text { Mottetto O laeta dies C.A.T.B. Viol(ini) 2. C(larini) 2. Org(ano) } \\ {[290]} & \text { No. 7. } & \text { Mottetto Gloria in Excelsis. CAT.B. Viol(ini) 2. C(larini) 2. Org(ano) } \\ {[291]} & \text { No. } 8 . & \text { Mottetto Natus est. CATB Viol(ini) 2. C(arini) 2. Org(ano) } \\ {[292]} & \text { No. 9. } & \text { Mottetto Grates nunc. C.A.T.B. Viol(ini) 2. C(larini) 2. Org(ano) } \\ {[293]} & \text { No. IO. } & \text { Item Grates triplex. CATB. Viol(ini) 2. C(larini) 2. Org(ano) } \\ {[294]} & \text { No. II. } & \text { Pastorella ex D. Alt(i) 2. Viol(ini) 2. Org(ano). Dormi Tenelle } \\ {[295]} & \text { No. I2. } & \text { Pastorella ex D. C(anto) solo. Viol(ini) 2. Org(ano). Eia mea anima. } \\ {[296]} & \text { No. I3. } & \text { Pastorella ex Dis. Salve Puelle C.A. V(iolini) 2. Obois solo Org(ano) } \\ {[297]} & \text { No. I4. } & \text { Pastorella ex B. Pupule tenelle C(anto) solo. Viol(ino) solo. Org(ano) } \\ {[298]} & \text { No. 15. } & \text { Offertorium. CA.T.B. 2 Viol(ini) Lit(ui) 2 Org(ano) } \\ & \text { No. I6 } & \text { [pozostawione puste miejsce] } \\ & \text { No. I7 } & \text { [pozostawione puste miejsce] }\end{array}$

Mottetto de Resurrectione
[299] No. I
Haec dies q(ua)m fecit D(omi)n(us) CATB. Viol(ini) 2. C(larini) 2. Org(ano)
[300] No. 2
Angelus D(omi)ni ex B. CATB. Viol(ini) 2. C(larini) 2. Org(ano)
[30I] No. 3 .
Alleluia ex D. CATB. Viol(ini) 2. C(larini) 2. Org(ano)

\footnotetext{
4I Breskiewicz? Kompozytor nieznany. Być może chodzi o Franciszka Braszkiewica, który uczył się w bursie jezuickiej w Krakowie w l. I722-25, a później był członkiem respektu, zob.: Iwona Tylka, „Instrumentaliści i wokaliści kapeli jezuickiej kościoła ss. Piotra i Pawła w Krakowie”, Liturgia Sacra $20(2014)$ nr 2, s. 436.
} 


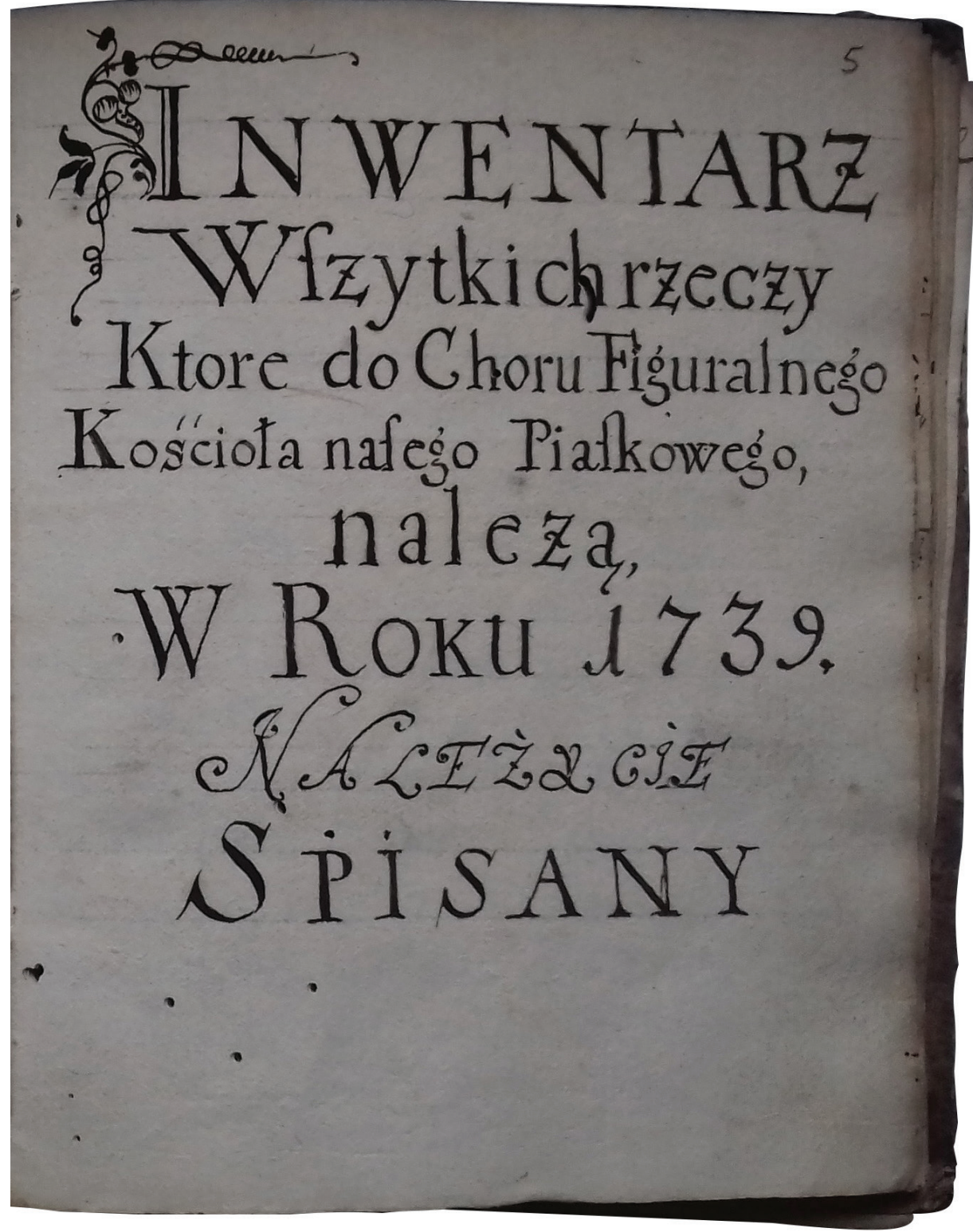

Il. I. Inwentarz muzyczny, I739 r., Archiwum Karmelitów w Krakowie na Piasku, sygn. AKKr 7ora, karta tytułowa (k. 5r)

42 Fotografie za zgodą Archiwum Karmelitów w Krakowie na Piasku 


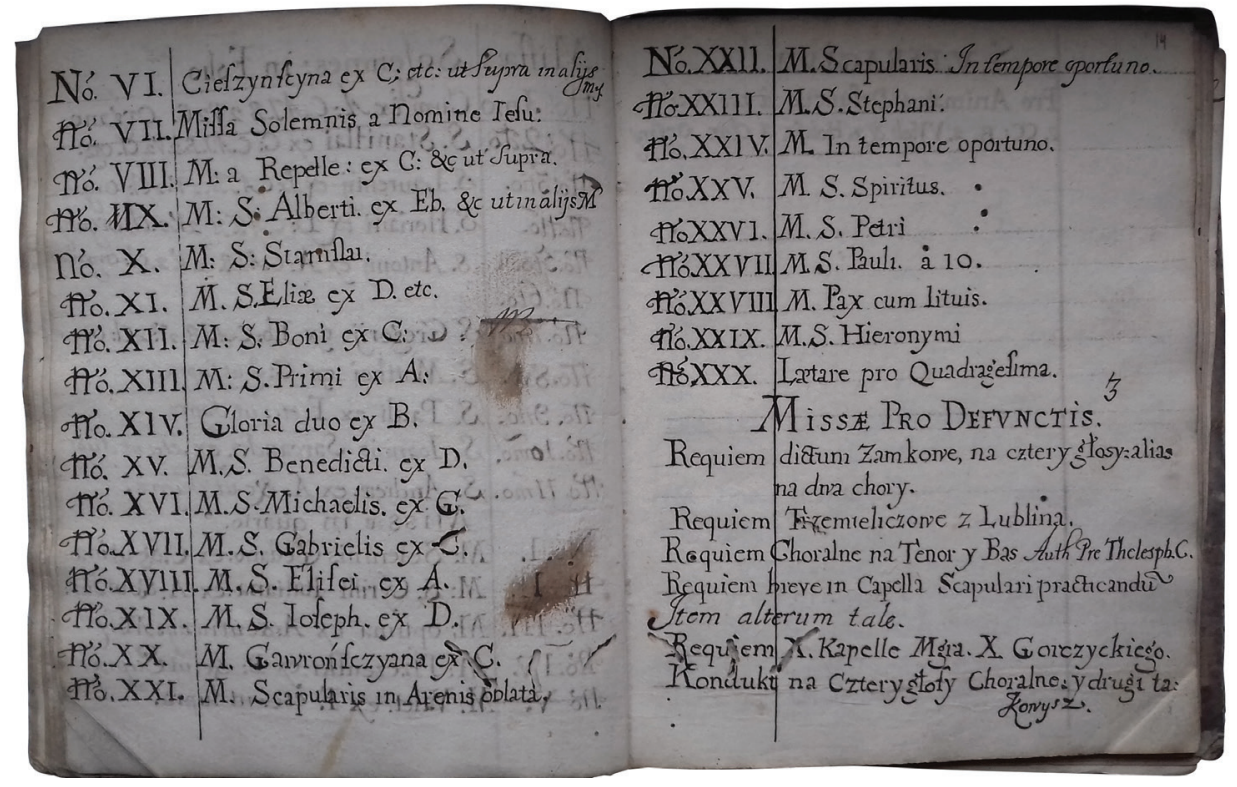

Il. 2. Inwentarz muzyczny, 1739 r., Archiwum Karmelitów w Krakowie na Piasku, sygn. AKKr 70ra, fragment dotyczący Missae in quarto (k. I3v-I4r)

\section{BIBLIOGRAFIA}

Byczkowska-Sztaba, Jolanta. Rękopisy i druki muzyczne z XVIII wieku w zbiorach Archiwum Opactwa Cystersów w Krakowie-Mogile [dokument elektroniczny]. Katalog tematyczny. Warszawa: Biblioteka Narodowa, 2013.

Chrzanowski, Tadeusz, Tadeusz Maciejewski, opr. Graduat karmelitański z I644 roku o. Stanistawa ze Stolca. Warszawa: Instytut Wydawniczy PAX, 1976.

Gołos, Jerzy. „Muzykalia biblioteki klasztoru Na Piasku w Krakowie”. Muzyka II, nr 3-4 (1966): 86-97.

Górski, Konrad, Jerzy Woronczak, opr. Zasady wydawania tekstów staropolskich. Projekt. Wrocław: Zakład Narodowy im. Ossolińskich, I955.

Grabiec, Dominika. „ «Ave Maris Stella» Szymona Ferdynanda Lechleitnera ze zbioru muzykaliów po klasztorze pijarów w Podolińcu”. Muzyka 57, nr 3 (20I2): 23I-242.

Grabiec, Dominika. „Offertoria Szymona Ferdynanda Lechleitnera ze zbiorów muzykaliów Biblioteki Wyższego Seminarium Duchownego w Sandomierzu”. Przeglad Muzykologiczny 6 (2006): 17-59.

Kochanowicz, Jerzy. Stownik geograficzny jezuickich burs muzycznych. Materiaty. Kraków: WAM, 2002.

Kolak, Wacław. Katalog Archiwum oo. Karmelitów w Krakowie „Na Piasku”. I398-1945 (I988). Kraków: Zakon oo. Karmelitów, 1997.

Konik, Marcin. „Muzyka religijna Johanna Valentina Rathgebera (I682-I750) w świetle źródeł polskich". Muzyka 53, nr 3 (2008): 3I-43. 
Lepszy, Kazimierz, red. Instrukcja wydawnicza dla źródet historycznych od XVI do potowy XIX wieku. Wrocław: Zakład im. Ossolińskich, 1953.

Maciejewski, Tadeusz. „Działalność muzyczna Bractwa Szkaplerznego w kościele oo. Karmelitów Trzewiczkowych w Krakowie na Piasku”. Muzyka 23, nr 2 (1978): 59-7I.

Maciejewski, Tadeusz. „Inwentarz muzykaliów kapeli karmelickiej w Krakowie na Piasku z lat 1665-I684", Muzyka 21, nr 2 (1976): 77-99.

Maciejewski, Tadeusz. „Kilka uwag o muzyce i muzykach z klasztoru oo. Karmelitów Trzewiczkowych w Trembowli”. W: Musica Galiciana. Kultura muzyczna Galicji w kontekście stosunków polsko-ukraińskich (od doby piastowsko-książęcej do roku 1945), red. Leszek Mazepa. T. 3, I27-I37. Rzeszów: Wydawnictwo Wyższej Szkoły Pedagogicznej, I999.

Maciejewski, Tadeusz. „Muzycy karmeliccy z lwowskiego Conventus Major”. W: Musica Galiciana. Kultura muzyczna Galicji w kontekście stosunków polsko-ukrainskich (od doby piastowsko-książęcej do roku 1945), red. Leszek Mazepa. T. 5, 23-44. Rzeszów: Wydawnictwo Wyższej Szkoły Pedagogicznej, 2000.

Maciejewski, Tadeusz. „O Eliaszu Karmelicie, Wawrzyńcu Zadorskim - warszawskim organmistrzu i Gabrielu Seneńskim - trębaczu”. Muzyka 22, nr 3 (I977): III-II5.

Maciejewski, Tadeusz. „Przyczynek do biografii Andrzeja Wołoszki (ca I70o-I757) i do historii kapel karmelickich". Muzyka 20, nr 2 (I975): 73-8I.

Matoga, Piotr. Organy w Bazylice oo. Karmelitów na Piasku w Krakowie. Lublin: Wydawnictwo Muzyczne Polihymnia, 20I4.

Nowak-Romanowicz, Alina. „Brixi”. W: Encyklopedia muzyczna PWM, red. Elżbieta Dziębowska. T. I, 422-423. Kraków: PWM, I979.

Patalas, Aleksandra. „Działalność i repertuar kapeli muzycznej w Rakowie Opatowskim w świetle źródeł archiwalnych". W: Muzyka religijna - między epokami i kulturami, red. Krystyna Turek, Bogumiła Mika. T. 2, 28-44. Katowice: Wydawnictwo Uniwersytetu Śląskiego, 2019.

Podejko, Paweł. Kapela wokalno-instrumentalna paulinów na Jasnej Górze. Kraków: PWM, I977.

Przybyszewska-Jarmińska, Barbara. „Szczurowski Jacek”. W: Encyklopedia Muzyczna PWM, red. Elżbieta Dziębowska. T. Io, 236-237. Kraków: PWM, 2007.

Sieprawski, Paweł. Justus germinavit. Plaudite sidera. Regina caeli, wyd. Maciej Jochymczyk. Kraków: Musica Iagellonica, 2012 (= Sub Sole Sarmatiae I4).

Szweykowski, Zygmunt M., red. Grzegorz Gerwazy Gorczycki. Studia I: katalog tematyczny. Kraków: PWM, 1986.

Tylka, Iwona. „Instrumentaliści i wokaliści kapeli jezuickiej kościoła ss. Piotra i Pawła w Krakowie". Liturgia Sacra 20, nr 2 (2014): 427-478.

Walter-Mazur, Magdalena. Figura i fraktem. Kultura muzyczna polskich benedyktynek w XVII i XVIII wieku. Poznań: PTPN, 2014. 


\section{A CARMELITE MUSIC INVENTORY FROM I739}

Recently discovered in the Carmelite Archive in the Piasek district of Kraków is a previously unknown inventory of music-related sources. Compiled in 1739, it lists around 260 pieces belonging to the music collection of the Carmelite ensemble in Kraków during the first half of the eighteenth century. This is a precious find, which fundamentally alters our knowledge of the ensemble's activity. Until now, the only source of information about its repertoire was an inventory from I660-84, published by Tadeusz Maciejewski in Muzyka in 1976, which contains an entirely different set of titles.

The eighteenth-century inventory lists the titles of Masses, litanies, motets, hymns and concertos, mostly without the composers' names. The few mentioned by name are either Polish composers or foreign musicians active in the Polish-Lithuanian Commonwealth during the first half of the eighteenth century, namely, Grzegorz Gerwazy Gorczycki, Jacek Szczurowski, Paweł Sieprawski, Józef Kobierkowicz, Szymon Ferdynand Lechleitner and Pszczeński (first name unknown), as well as the Central-European composers Johann Valentin Rathgeber and Šimon Brixi. The inventory lists several pieces by these composers not known from any other sources.

Translated by Tomasz Zymer

Słowa kluczowe / key words: Karmelici / Carmelites, Kraków, inwentarz muzykaliów / music inventory, XVIII wiek / I8th century

Dr Marek Bebak - muzykolog, bibliotekarz i archiwista. Adiunkt w Instytucie Muzykologii Uniwersytetu Jagiellońskiego. Jego zainteresowania naukowe koncentrują się wokół kultury muzycznej Krakowa w XVII-XVIII wieku. W roku 2018 opublikował monografię Franciszek Lilius. Życie i twórczość na tle epoki (Kraków, Musica Iagellonica), a dwa lata wcześniej edycje kompozycji tego twórcy (w serii „Sub Sole Sarmatiae” 27, 28). marek.bebak@gmail.com

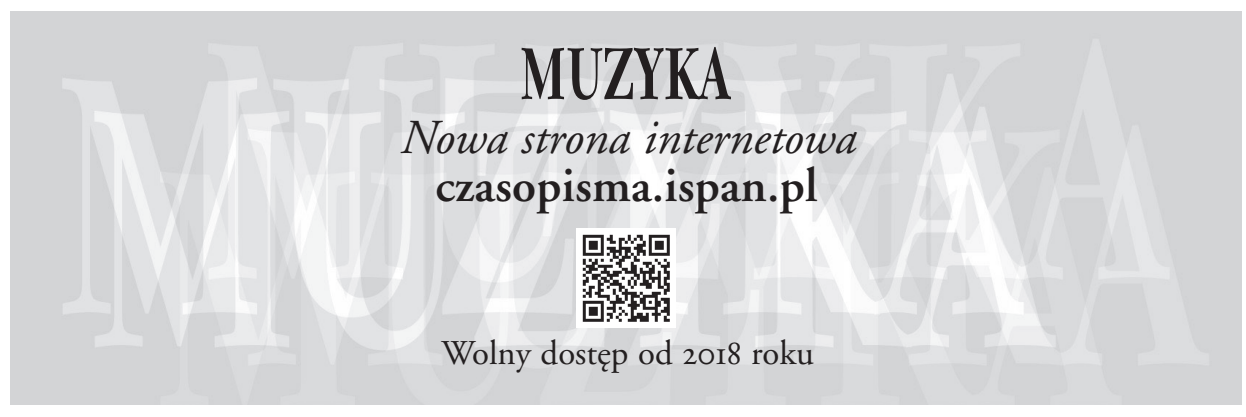


